Psicologia Escolar

e Educacional
ARTIGO

DOI: http://dx.doi.org/10.1590/2175-35392020202380

Elocid - e202380

\title{
A INFLUÊNCIA DA CRENÇA DE AUTOEFICÁCIA NO DESEMPENHO DOS ALUNOS DO IFMG - BAMBUÍ
}

\author{
Adalberto Nunes de Menezes $^{1} \mathbb{D}$; Bruna de Melo Alves ${ }^{1} \mathbb{D} ;$; Rosemary Pereira Costa e Barbosa ${ }^{1} \mathbb{D} ;$ Patrícia Carvalho \\ Campos $^{1} \mathbb{D}$;
}

\section{RESUMO}

Autoeficácia é um conceito da Teoria Social Cognitiva que trata da capacidade da própria pessoa se organizar e executar ações para atingir metas. Neste estudo foi desenvolvida uma pesquisa que procurou averiguar os motivos que denotam baixo desempenho de alunos quando cursando a disciplina de Cálculo. Uma das hipóteses investigadas trata da avaliação da influência das crenças de autoeficácia utilizando como campo de estudo o corpo discente do IFMG - Campus Bambuí. A pesquisa foi desenvolvida com base na aplicação de duas etapas distintas de cunho descritivo e qualitativo que levaram em conta o início e o final das disciplinas. Os resultados apontaram a existência de crenças de autoeficácia nos alunos iniciantes que se fortaleceram nos alunos concluintes. Com base nisso, pode-se destacar a importância do professor no processo de formação da autoeficácia do aluno, a necessidade de se desenvolver novas metodologias e, também, a relevância do suporte pedagógico e psicológico.

Palavras-chave: Autoeficácia; rendimento escolar; Teoria Social Cognitiva.

\section{The influence of self-efficacy beliefs in the performance of students at IFMG - Bambuí}

\begin{abstract}
Self-efficacy is a concept of Cognitive Social Theory that addresses one's ability to organize and take action to achieve goals. In this study was developed a research that sought to ascertain the reasons that denote poor performance of students when studying the discipline of Calculus. One of the hypotheses investigated deals with the evaluation of the influence of self - efficacy beliefs using as a field of study the students of IFMG - Campus Bambuí. The research was developed based on the application of two distinct descriptive and qualitative steps that took into account the beginning and end of the disciplines. The results pointed to the existence of self-efficacy beliefs in the beginning students that became stronger in the finishing students. Based on this, we can highlight the importance of the teacher in the process of forming student self-efficacy, the need to develop new methodologies, also the relevance of pedagogical and psychological support.
\end{abstract}

Keywords: Self-efficacy; academic performance; Cognitive Social Theory.

\section{La influencia de la creencia de autoeficacia en el desempeño de los alumnos del IFMG -Bambuí}

\section{RESUMEN}

Autoeficacia es un concepto de la Teoría Social Cognitiva que trata de la capacidad de la propia persona organizarse y ejecutar acciones para alcanzar objetivos. En este estudio se desarrolló una investigación que buscó averiguar los motivos que denotan bajo desempeño de alumnos cuando están cursando la asignatura de Cálculo. Una de las hipótesis investigadas trata de la evaluación de la influencia de las creencias de autoeficacia utilizando como campo de estudio el equipo discente del IFMG - Campus Bambuí. La investigación se desarrolló con base en la aplicación de dos etapas distintas de cuño descriptivo y cualitativo que llevaron en cuenta el inicio y el final de las asignaturas. Los resultados apuntaron la existencia de creencias de autoeficacia en los alumnos iniciantes que se reforzaron en los alumnos concluyentes. Con base en eso, se puede destacar la importancia del profesor en el proceso de formación de la autoeficacia del alumno, la necesidad de desarrollarse nuevas metodologías y, también, la relevancia del soporte pedagógico y psicológico.

Palabras clave: Autoeficacia; rendimiento escolar; Teoría Social Cognitiva.

${ }^{1}$ Instituto Federal de Minas Gerais - Bambuí - MG - Brasil; adalbertomenezes1@gmail.com; brunameloa1@outlook.com; rose. costa@ifmg.edu.br; patricia.campos@ifmg.edu.br 


\section{INTRODUÇÃO}

As disciplinas relacionadas à matemática são consideradas difíceis pela maioria dos estudantes de graduação. Sabe-se que o índice de reprovação nessas disciplinas é alto e existem diversos fatores, inclusive psicológicos que podem afetar tal desempenho, influenciando diretamente na aprendizagem do aluno. A Teoria Social Cognitiva (TSC), proposta por Albert Bandura, trabalha conceitos que nos instrumentalizam para o entendimento desses possíveis fatores psicológicos que podem vir a afetar e/ou influenciar a aprendizagem dos alunos.

Segundo Torisu (2010), a dificuldade dos alunos em disciplinas ligadas ao Cálculo é bastante elevada, e isso não é apenas um problema do Brasil. Pesquisas comprovam que os índices de reprovação nas disciplinas de Cálculo são elevados também em outros países (Torisu, 2010; Souza \& Brito, 2008; Garzella, 2013; Rocha, 2011). Vários fatores podem influenciar nesses resultados negativos obtidos pelos alunos. Nesse sentido, observa-se que um fator determinante para o sucesso no processo de aprendizagem é a crença de autoeficácia que o aluno constrói acerca da disciplina em questão.

O conceito de autoeficácia foi desenvolvido pela Teoria Social Cognitiva (TSC). Nessa teoria, a autoeficácia é fator determinante no comportamento que um indivíduo terá em relação a alguma situação. Ela influencia diretamente na capacidade da agência humana, na qual o indivíduo escolhe o modo de agir, influenciando o próprio funcionamento e as circunstâncias de sua vida de modo intencional (Pajares \& Olaz, 2008).

Souza e Brito (2008) explanam que, em nível mundial, as pesquisas sobre a influência da autoeficácia na aprendizagem são satisfatórias e vêm crescendo continuamente, mas ressaltam também que, no Brasil, esses estudos ainda são escassos, o que interfere na construção de um diagnóstico sobre a realidade escolar dos alunos, em especial daqueles de disciplinas relacionadas à matemática.

O IFMG é uma instituição federal de ensino que oferece cursos na modalidade superior, técnico e de pós-graduação. Em Bambuí/MG, o IFMG oferece os cursos de Bacharelado em Engenharia de Computação, de Produção e de Alimentos e em Administração; Licenciatura em Biologia e em Física; Agronomia, Zootecnia, vários cursos técnicos e um mestrado profissional na área de meio ambiente. Desses cursos superiores, a maioria possui a disciplina de Cálculo em suas matrizes curriculares.

De acordo com dados obtidos na Secretaria Acadêmica do IFMG - Campus Bambuí, o desempenho dos alunos apresenta-se bastante comprometido na disciplina de Cálculo I, apresentando uma taxa de 72,69\% de reprovação no segundo semestre de 2015.
Esse desempenho pode estar relacionado com a crença que os estudantes possuem sobre suas capacidades e se conseguiram um bom desempenho ou não na disciplina. Considerando esse fator e o baixo desempenho dos alunos do IFMG -- Campus Bambuí nas disciplinas relacionadas ao Cálculo e os conceitos de autoeficácia presentes na Teoria Social Cognitiva, o presente artigo propõe apresentar os resultados da pesquisa desenvolvida sobre as crenças de autoeficácia dos alunos que cursaram as disciplinas de Cálculo no IFMG - Campus Bambuí no segundo semestre de 2016.

De acordo com Azzi e Polydoro (2006), Albert Bandura em seus estudos evidencia a autoeficácia como o julgamento da própria pessoa em ter a capacidade de se organizar e executar ações para atingir metas. Ainda de acordo com os autores supracitados, em 1977, Bandura já propunha sua teoria da autoeficácia, quando trabalhava em tratamento de fobias com técnicas de modelamento na aprendizagem (Azzi \& Polydoro, 2006). Assim, Bandura inferiu que a crença de cada um levava diretamente a alterações psicológicas (estresse e depressão) que a pessoa suportava em situações de ameaça, e isso influenciava no nível de motivação.

Segundo Azzi e Polydoro (2006), o conceito de autoeficácia aponta um fenômeno de caráter subjetivo (crenças) sobre possibilidades pessoais (crenças de capacidade) de produzirem a própria trajetória de forma agêntica (organizar e executar), relacionando a concepção de autoeficácia a metas e objetivos (produzir certas realizações). Assim, os autores explanam que há um foco de avaliação circunscrito a um domínio específico da intenção e ação do indivíduo, havendo percepções de elevada autoeficácia para algumas situações de domínio, e baixa para outras.

De acordo com Bandura (1997), a avaliação adequada de autoeficácia, diante de domínio e contextos particulares, envolve o julgamento da capacidade em três dimensões: magnitude, força e generalidade. A magnitude envolve os diferentes níveis de dificuldades presentes no domínio da atividade; já a força descreve a intensidade da crença do indivíduo perante os diferentes aspectos de domínio; e a generalidade refere-se à amplitude das crenças relacionadas a domínios específicos. Assim, as crenças de autoeficácia referem-se ao julgamento de alguém em lidar com determinada situação (Azzi \& Polydoro, 2006).

Conforme indicado por Azzi (2014), as percepções de eficácia produzem efeitos na agência humana através de quatro processos: cognitivo, motivacional, afetivo e de escolha. O processo cognitivo é regulado pelo pensamento antecipatório, formulando, nessa antecipação, objetivos pessoais, sendo que, quanto mais forte a percepção de autoeficácia, mais altos são os desafios que as pessoas estabelecem para si mesmas. Já o processo motivacional refere-se ao ato das pessoas se automo- 
tivarem e guiarem suas ações, formando crenças sobre o que podem fazer.

O processo afetivo, por sua vez, afeta o volume de estresse e de depressão que as pessoas experimentam em situações difíceis ou ameaçadoras, bem como seu nível motivacional. E por último, o processo de escolha, no qual as pessoas evitam as situações em que acreditam exceder suas capacidades, mas se comprometem com atividades desafiadoras e escolhem situações com as quais se julgam capazes de lidar (Boruchovitch \& Bzuneck, 2009).

No entanto, de acordo com Torisu e Ferreira (2009), não é correto dizer que somente possuir elevadas crenças de autoeficácia seja suficiente para garantir o sucesso na realização de determinada atividade. Essas crenças, aliadas aos conhecimentos prévios e a uma capacidade cognitiva adequada, servirão de base para a motivação e o sucesso.

Segundo Bandura (1986), o indivíduo constrói suas próprias crenças de autoeficácia em diferentes domínios a partir de interpretações de informações obtidas em quatro fontes que dão origem a essas crenças, podendo atuar de forma independente ou em conjunto. São elas: experiência direta, experiência vicária, persuasão social, estado físico e emocional.

A maneira mais eficaz de criar um senso forte de eficácia é por meio da experiência direta, que se relaciona com as experiências vividas (Azzi \& Polydoro, 2006). Os sucessos constroem uma opinião positiva sobre sua eficácia pessoal. Por outro lado, as falhas a comprometem, principalmente, se não há um sentimento de eficácia firmemente estabelecido (Bandura, 1994).

Outra forma de fortalecer as crenças de autoeficácia são as experiências vicárias, que são fornecidas por modelos sociais. De acordo com Costa (2008), o indivíduo, ao observar as atitudes dos outros, baseia-se numa avaliação entre as características do modelo e as suas. Assim, observando as consequências daquela ação, sendo positivas ou negativas, pode vir a adotar aquele comportamento, caso haja uma identificação com o modelo, tendo-o como referência.

A persuasão social também é uma das maneiras de fortalecer a crença das pessoas para realizar determinada tarefa. Na realização desta, a autoeficácia pode-se desenvolver quando, de alguma forma, for comunicado ao sujeito que ele tem capacidade para realizar a atividade em questão (Boruchovitch \& Bzuneck, 2009). Pajares e Olaz (2008) reforçam a ideia de que a persuasão social é uma maneira de fortalecer as crenças de autoeficácia e defendem que o desenvolvimento das crenças de eficácia depende ativamente dos persuasores. Para eles, quando há persuasões positivas, o indivíduo se sente encorajado, enquanto persuasões negativas enfraquecem o indivíduo, diminuindo a sua crença de autoeficácia. As pessoas também contam com seus estados físicos e emocionais para o juízo sobre suas capacidades. Poy et al. (2004) dizem que parte do julgamento sobre as capacidades do indivíduo é sustentada pelos seus estados emocionais.

Segundo Bandura (1994), o mau desempenho é considerado pelos indivíduos como reação de estresse e tensão. Assim, não é a pura intensidade das reações emocionais e físicas que importa, mas como é percebida e interpretada (Barros \& Santos, 2010). Pessoas que possuem alto senso de autoeficácia consideram seus estados de excitação como facilitadores para o desempenho. No entanto, pessoas com autodúvidas julgam sua excitação como um impedimento para seu desenvolvimento (Barros \& Santos, 2010).

Os diversos autores citados (Azzi \& Polydoro, 2006; Pajares \& Olaz, 2008; Barros \& Santos, 2010; Poy et al., 2004) concordam com Bandura ao perceber como as experiências diretas, as experiências vicárias, as persuasões sociais e verbais e os estados físicos e emocionais são fundamentais para o fortalecimento ou o enfraquecimento das crenças de capacidade do indivíduo, construindo a sua autoeficácia.

Em relação à aprendizagem, diversas pesquisas apontam que a persistência do aluno é consequência de suas percepções positivas em relação a si mesmo. Estudantes que possuem maior crença em suas capacidades conseguem persistir mais diante de dificuldades, aceitam tarefas desafiadoras, limitam menos suas escolhas e possuem níveis mais baixos de ansiedade (Pajares, 1996).

Pajares e Schunk (2004) explanam que essas pesquisas demonstram que a autoeficácia é altamente aplicável ao contexto educativo, exercendo uma influência significativa sobre os pensamentos e ações de alunos e professores, podendo influenciar na aprendizagem, na motivação e na realização dos alunos.

Com relação à matemática, as crenças de eficácia têm sido em geral, estudadas no contexto de soluções de problemas, ansiedade em relação a testes matemáticos e escolhas de carreiras relacionadas a essa área (Azzi \& Polydoro, 2006). As autoras complementam que as crenças de autoeficácia são um importante mediador na solução de problemas matemáticos. Isso significa que estudantes que acreditam que podem realizar uma tarefa vão continuar persistindo na atividade mesmo se encontrarem dificuldades, utilizando uma variedade de estratégias diferentes até alcançarem a solução do problema (Shih \& Alexander, 2000).

\section{MÉTODO}

O presente trabalho é um recorte de uma pesquisa realizada como Iniciação Científica no IFMG Campus Bambuí - MG, nos anos de 2016 e 2017. Tal pesquisa 
teve como objetivo avaliar a influência das crenças de autoeficácia no desempenho dos alunos das disciplinas de cálculo no IFMG - Campus Bambuí no segundo semestre de 2016. Realizou-se um estudo de caso qualitativo e descritivo dos alunos em dois momentos diferentes da disciplina. Buscou-se traçar o perfil dos discentes e descrever as crenças de autoeficácia no início e no fim da disciplina e a influência das crenças de autoeficácia sobre o desempenho dos alunos.

Quanto aos procedimentos técnicos, a pesquisa utilizou questionários. Os questionários utilizados balizaram-se nos instrumentos desenvolvidas por Pires (2008) e Torisu (2010), que também pesquisaram as crenças de autoeficácia em relação ao desempenho escolar.

Os questionários foram elaborados com um total de 10 questões divididas em 04 categorias, de acordo com os objetivos: identificação, percepção sobre o rendimento escolar, percepção do desempenho na disciplina de Cálculo e a influência da relação professor/aluno no desempenho na disciplina. Nos questionários, as respostas foram dadas na modalidade de resposta fechada, tipo Likert de 1 a 5 e questões de múltipla escolha. Em questões relacionadas à percepção de desempenho e relação professor/aluno, havia espaço para justificativas.

Os questionários aplicados possuíam as quatro categorias citadas. No entanto, seus objetivos eram distintos: o primeiro questionário visava a expectativa do aluno ao iniciar a disciplina; o questionário, aplicado aos alunos concluintes, continha questões relativas ao sucesso do aluno, o que contribuiu para o seu êxito e seu sentimento ao concluir a disciplina.

Inicialmente, pela leitura dos dados obtidos na Secretaria Acadêmica do IFMG- Campus Bambuí, foram identificados quatro cursos que ofertavam a disciplina de Cálculo no primeiro semestre de 2016, sendo eles: Engenharia de Alimentos, Engenharia de Computação, Licenciatura em Física e Zootecnia. Esses possuíam, respectivamente, 41, 33, 54, 47 alunos matriculados. No entanto, os sujeitos de pesquisa se caracterizam, na primeira etapa da pesquisa, pelos alunos que estavam cursando a disciplina de Cálculo pela primeira vez sendo: 16 do curso de Engenharia de Alimentos, 21 de Engenharia de Computação, 7 de Física e 28 de Zootecnia; totalizando 72 alunos iniciantes na disciplina. E na segunda etapa, pelos alunos concluintes da disciplina de Cálculo.

É relevante observar que os alunos concluintes não são os alunos aprovados na disciplina. Denominaram-se concluintes os alunos que permaneceram na disciplina até sua última prova, foram 26 alunos, sendo: 11 do curso de Engenharia de Alimentos, 10 de Engenharia de Computação, 3 de Física e 2 de Zootecnia.

Os alunos aprovados na disciplina foram 17, a saber:
3 alunos do curso de Engenharia de Alimentos, 8 do curso de Engenharia da Computação, 5 da Licenciatura em Física e 1 aluno do Bacharelado em Zootecnia. Assim, em relação aos alunos participantes da pesquisa, neste semestre, na disciplina de Cálculo, houve um índice de $23,16 \%$ de aprovação. Durante a pesquisa, 19,44 $\%$ dos alunos que a iniciaram deixaram de participar. Assim, a pesquisa teve $80,56 \%$ de adesão dos alunos em suas etapas.

Quanto à aplicação dos questionários, a primeira etapa foi desenvolvida no mês de agosto de 2016, no início do período letivo, tendo como objetivo analisar a autoeficácia dos alunos ao iniciarem a disciplina de Cálculo. Os alunos foram inicialmente informados acerca do objetivo geral do estudo, a confidencialidade e o anonimato dos dados fornecidos, bem como sobre a importância da sua colaboração e sinceridade das suas respostas. Sempre que necessário, foram esclarecidas dúvidas relativas ao questionário. A etapa relacionada aos alunos concluintes foi realizada com os alunos nos meses de dezembro de 2016 e janeiro de 2017.

Após a coleta dos dados, esses foram processados no Google Formulários. As questões incompletas foram categorizadas como não respondidas, e os questionários foram categorizados de acordo com a letra do curso e o número de alunos (Ex: $Z 1$ - respondente número 1 do curso de Zootecnia, e assim sucessivamente). Com a planilha em mãos, iniciou-se o processo de tabulação e agrupamento de dados, onde foi inicialmente feita a análise do perfil dos alunos, analisando a maior predominância de curso, sexo e idade.

Foram analisados a autopercepção do aluno enquanto estudante, o seu rendimento escolar, a frequência de estudos em casa e o sentimento ao realizar provas. Além desses fatores, a análise baseou-se na percepção do aluno quanto às disciplinas de Cálculo, suas dificuldades em relação a elas e as suas expectativas para iniciar a disciplina. E, por fim, foi analisado o que os alunos acham da relação professor/aluno e como essa relação pode influenciar em seu desempenho. Os resultados foram interpretados com base na teoria estudada e já apresentada no referencial teórico.

\section{RESULTADOS E DISCUSSÕES Cálculo \\ Questionário - alunos iniciantes na disciplina de}

Em relação ao perfil dos alunos pesquisados, foi possível observar que $57,40 \%$ são do sexo masculino, com idade entre 19 e 20 anos (65,00\%) e que acreditam ter melhor aproveitamento na área de Exatas (53,60\%). Notou-se ainda que a maioria - $34,78 \%$ dos alunos respondentes - pertencia aos cursos de Bacharelado em Zootecnia (34,78\%) e Engenharia de Computação (30, $43 \%)$, estando no segundo período.

Quanto à autopercepção enquanto aluno, 95,6\% 
afirmaram serem alunos bons ou médios, sendo que apenas $4,40 \%$ disseram não serem bons alunos. Esse índice positivo pode estar relacionado à frequência de estudos em casa, onde a maioria mencionou estudar em casa, $73,09 \%$ estudando não só no momento das provas, e somente $1,50 \%$ afirmaram não estudar. Quanto ao sentimento em fazer prova, $63,8 \%$ julgaram que as fariam bem, e apenas $36,20 \%$ sentiam-se nervosos e acreditavam que poderiam se confundir devido a isso. Esses dados demonstram que os alunos, ao iniciarem a disciplina, apresentam percepção positiva em relação a sua atuação, o que pode alicerçar e reforçar sua crença de autoeficácia.

Sobre a disciplina, pôde-se notar que, embora os alunos considerem as disciplinas relacionadas ao Cálculo difíceis, eles apresentaram uma autoeficácia positiva nesse domínio, sendo que a maioria acreditava que conseguiria aprendê-la $(78,30 \%)$ e que iria ser aprovada $(81,20 \%)$. Os alunos representaram a autoeficácia positiva desse momento inicial, com o pensamento de que acreditavam que poderiam tirar notas boas na disciplina $(59,00 \%)$, e outros (15\%) ainda pontuaram que, apesar da dificuldade do conteúdo, acreditavam que poderiam entendê-lo, resolver as questões e tirar boas notas.

Essa percepção se confirma, pois a maior parte dos alunos, $52,20 \%$, afirmou que se sentia confiante ou muito confiante ao iniciar a disciplina de Cálculo. Ainda sobre a disciplina, os alunos responderam que acreditavam que há influência da forma de estudo em seu desempenho $(97,10)$, sendo que $36,11 \%$ deles justificaram que, se estudassem bastante, a nota seria melhor.

Sobre a relação professor/aluno, os respondentes $(65,20 \%)$ mencionaram que, quando essa relação é boa, influencia positivamente em seu desempenho e em seus estudos. Observa-se, nessas respostas, a importância do professor na formação da crença de autoeficácia dos alunos.

\section{Questionário II - alunos concluintes da disciplina de Cálculo}

Aqui, serão analisados os dados dos alunos que realizaram todas as provas e atividades propostas na disciplina de Cálculo, ou seja, que persistiram na disciplina até o seu término, independentemente de terem sido aprovados ou não. Foram pesquisados 27 alunos, o que corresponde a $39,13 \%$ dos alunos que iniciaram a pesquisa (69 alunos).

Em relação ao perfil dos entrevistados, percebeu-se que a maior parte dos respondentes é do sexo masculino $(67,00 \%)$. No questionário I (alunos iniciantes), a diferença de porcentagem entre homens e mulheres foi somente de $14,8 \%$, e agora foi de $34 \%$. Esse dado poder estar relacionado à questão de gênero na escolha das profissões ligadas às áreas de Ciências Exatas (Azzi \& Polydoro, 2006). A maior parte dos respondentes estava na faixa etária de 19 e 20 anos $(48,00 \%)$ e era estudante de Engenharia de Alimentos e de Computação ( $37,00 \%$ cada um).

Os estudantes pesquisados se consideravam alunos bons e médios $(92,60 \%)$ e acreditavam que conseguiriam concluir a disciplina de Cálculo com êxito $(85,20 \%)$. Embora tivessem uma autopercepção positiva em relação ao seu desempenho acadêmico e aparentemente tenham desenvolvido uma crença de autoeficácia positiva em relação ao Cálculo, é importante ressaltar que $55,60 \%$ sentiam-se apreensivos quando iriam fazem prova dessa disciplina, embora acreditassem que conseguiriam. Porém, aproximadamente um terço dos alunos $(29,60 \%)$ sentia-se tranquilo, pois estava ancorado pelos estudos realizados.

Observa-se que, se o esforço é muito grande na consecução do objetivo, as crenças de autoeficácia se fragilizam em relação ao domínio, como parece demonstrar a apreensão dos alunos em relação às provas. Percebe-se, porém, em contrapartida, que as experiências de sucesso motivam os alunos e fortalecem as crenças de autoeficácia. Assim, eles se autorregulam em relação ao comportamento de estudo. Os discentes respondentes apontaram que estudavam alguns dias na semana para a disciplina $(96,70 \%)$ e afirmaram que o estudo influenciou seu desempenho $(92,60 \%)$, justificando que, quanto mais estudavam, maior o domínio na disciplina $(65,40 \%)$.

A análise dos resultados aponta que os alunos desenvolveram uma autoeficácia positiva em relação à disciplina $(85,20 \%)$ e que acreditavam que seriam aprovados, mas a experiência direta não é suficiente para sustentar a autoeficácia em relação a outras disciplinas de Cálculo (46,70\%) estão pouco confiantes em relação a iniciar outra disciplina de cálculo.

Os respondentes apontaram que os fatores que mais influenciaram o seu desempenho na disciplina de Cálculo foram a didática utilizada pelo professor, a percepção da possibilidade de sucesso (experiência direta) e a observação de alunos que se saíram bem na disciplina (experiência vicária).

Assim como nos questionários I e II (alunos iniciantes e alunos desistentes), os alunos respondentes mencionaram que existe uma influência direta da relação professor-aluno com o desempenho na disciplina. Eles acreditam que, quando essa relação é boa, ela ajuda no desempenho e na sua vontade de estudar $(92,60 \%)$. Outro ponto bastante relevante para eles refere-se à didática utilizada pelo professor.

Análise final - Correlação dos resultados dos dois grupos de alunos (iniciantes e concluintes)

Nesta seção, foi realizada uma comparação dos resultados obtidos com a aplicação dos dois questionários para os alunos iniciantes (questionário 1) e 
concluintes (questionário 2) da disciplina de Cálculo I dos Cursos Superiores do IFMG - Campus Bambuí. Para se fazer essa análise colocaram-se como referência os objetivos específicos da pesquisa, a saber: identificar a presença de crenças de autoeficácia nos alunos da disciplina de Cálculo; elencar as formas de estudo dos alunos nas disciplinas de Cálculo; analisar a influência das metodologias de ensino de Cálculo no desempenho e na formação de autoeficácia dos alunos; descrever a relação professor-aluno na disciplina de Cálculo e sua influência no desempenho dos alunos; propor estratégias para o desenvolvimento da autoeficácia nos alunos da disciplina de cálculo do IFMG - Campus Bambuí.

Os alunos respondentes da pesquisa aprovados na disciplina de Cálculo foram somente 17. Assim, em relação aos alunos participantes da pesquisa, nesse semestre, na disciplina de Cálculo I, houve um índice de $23,16 \%$ de aprovação. Quanto ao perfil dos alunos pesquisados, fizeram-se perguntas relacionadas ao curso, ao sexo e à idade.

Em relação ao curso, observou-se que aquele com maior quantidade de alunos iniciantes foi o curso de Zootecnia. Já em relação aos alunos concluintes, os cursos que tiveram maior representatividade foram os da área de Engenharia (Engenharia de Alimentos e Engenharia de Computação).

Observou-se também que a maioria dos alunos que iniciaram a disciplina é do sexo masculino, e, consequentemente, os alunos concluintes também. Segundo Pinto, Carvalho e Rabay (2012), as relações de gênero podem direcionar e limitar as aspirações e escolhas profissionais dos/as jovens estudantes.

Por fim, em relação à idade, verificou-se uma semeIhança entre os alunos iniciantes e concluintes, apresentando alunos mais jovens, com idade entre 19 e 20 anos.

Antes de passar à identificação das crenças de autoeficácia nos alunos respondentes, é importante evidenciar como elas se desenvolvem. Aparentemente, é um processo simples, mas bastante inferencial e subjetivo. O sujeito (aluno) se empenha em uma ação, interpreta seus resultados e, a partir da percepção destes, desenvolve a crença sobre sua capacidade no dado domínio. Todo o processo é perpassado por influências internas (estados emocionais e físicos) e externas (experiências diretas, experiências vicariantes e persuasões verbais). Assim, pode-se afirmar que a autoeficácia, em dado domínio, é um fenômeno mutável e que sofre uma interferência direta do ambiente, como se observou nos resultados apresentados na presente pesquisa.

Em relação à identificação de crenças de autoeficácia nos alunos pesquisados, notou-se que estas são perceptíveis no grupo dos alunos iniciantes e concluintes. Eles apresentam autoeficácia positiva em relação ao domínio do Cálculo, apesar de afirmarem que a disciplina é difícil.
Porém, a autoeficácia construída, principalmente no grupo de alunos concluintes, é cambiante e se enfraquece em alguns momentos, como aponta o fato de os discentes não se mostrarem confiantes em relação a iniciar outras disciplinas da mesma área. Observa-se que eles não consideram ter autoeficácia no grau desejado para ingressar em uma nova disciplina de Cálculo, apesar de terem construído um autoconceito positivo em relação à área de Ciências Exatas.

A Teoria Social Cognitiva aponta que, quando o sucesso é alcançado com grau elevado de esforço, contribui pouco para o fortalecimento da autoeficácia, pois o aluno julga não possuir as habilidades importantes para lidar com o domínio, pois precisou despender muito esforço para obter o sucesso. Pode-se inferir que tal fato ocorreu com os alunos concluintes. Vale mencionar também que as crenças de autoeficácia diferem das expectativas de resultado e, embora o aluno possa ter uma crença de autoeficácia desenvolvida diante do domínio, ele pode ter expectativas de resultado negativas, uma vez que estas estão também ligadas ao contexto (ambiente, horário das aulas, grupo de alunos, didática e estratégias utilizadas pelo professor etc.) e, sobre esses fatores, o aluno sabe que não tem controle (Boruchovitch \& Bzuneck, 2009).

Na correlação entre as crenças de autoeficácia e sua influência sobre os estudos, observou-se que as crenças de autoeficácia influenciaram o esforço despendido pelos alunos no estudo e nas estratégias utilizadas para a sua realização, uma vez que se sabe que a autoeficácia interfere na motivação dos alunos em relação aos estudos. Assim, observou-se que os alunos, nas fases da pesquisa (iniciantes e concluintes), afirmaram a influência e a importância dos estudos para o sucesso na disciplina e apontaram a maneira de estudar como um dos fatores de sucesso. Observou-se que o tempo disponibilizado para o estudo dos alunos iniciantes e concluintes não divergem entre si. Os primeiros afirmam estudar mais de um dia na semana $(73,09 \%)$ e os concluintes $(96,70 \%)$, e eles disseram que o domínio da disciplina tem ligação direta com o maior tempo de estudo (iniciantes $36,11 \%$; concluintes $65,40 \%$ ).

Foi possível perceber uma elevação do percentual de estudo nos alunos concluintes, o que condiz com a teorização de TSC de que, quanto mais positiva a crença de autoeficácia, maior a autorregulação do aluno que traça cursos de ação mais eficazes e tem mais perseverança em relação aos desafios encontrados.

Ficou evidenciado, na pesquisa, que a forma de estudar mais utilizada por todos os alunos é fazer exercícios e assistir a videoaulas. Eles ainda pontuaram que a maneira de estudar é importante para o sucesso na disciplina, e alguns avaliam que estudar da forma errada pode prejudicar no desempenho, mas não esclarecem o que seria estudar de forma errônea. Eles não relataram 
participação em grupos de estudo ou monitoria.

Pôde-se observar que a forma e a frequência dos estudos têm relação com o sentimento dos discentes para fazer as provas da disciplina. Nota-se uma crença de autoeficácia positiva dos alunos iniciantes e concluintes em relação às avaliações $(63,80 \%$ dos iniciantes tinham a expectativa de que as fariam bem; $55,60 \%$ dos concluintes sentiam-se apreensivos, mas acreditavam que conseguiriam; e um terço dos alunos concluintes sentia-se tranquilo ao realizarem as provas, ancorados em seus estudos).

Foi um fator relevante na pesquisa a influência das metodologias de ensino de Cálculo no desempenho e na formação de autoeficácia dos alunos. Essa influência pode ser detectada de forma unânime no estudo. O grupo de alunos concluintes qualificou a didática utilizada em sala de aula pelo professor como um dificultador no aprendizado da disciplina. Sendo assim, foi possível verificar que a didática utilizada em sala de aula é fundamental para esse grupo de alunos na construção e na manutenção das crenças de autoeficácia.

A importância da atuação do professor foi retomada quando os alunos descreveram a relação professor-aluno na disciplina de Cálculo como tendo uma influência direta em seu desempenho. Essa percepção foi também unânime nos dois grupos de alunos, sendo que eles afirmaram que, quando ela é boa, influencia positivamente em seu desempenho e em seus estudos (essa influência é descrita por $65,20 \%$ dos alunos iniciantes e $92,60 \%$ dos alunos concluintes). Vale ressaltar aqui o aumento do percentual para os alunos concluintes. Cabe refletir se os alunos não confundem a relação afetiva com o professor com a didática desenvolvida por ele em sala de aula. Mas, como se sabe que a aprendizagem é facilitada pelos componentes emocionais positivos envolvidos na relação professor/ aluno, é importante se atentar para esse achado da pesquisa e observar que ele tem uma relação implícita com a formação e a manutenção da autoeficácia dos alunos em relação ao domínio pesquisado.

A TSC aponta a importância do professor em fazer os alunos perceberem seus progressos. Os feedbacks fornecidos pelos professores surgem como fundamentais no processo de formação e manutenção de autoeficácia dos alunos. Sabe-se que a persuasão verbal é um dos componentes de formação da autoeficácia, mas, por si, só não tem efeito duradouro. Então, o professor deve ter clareza de que o feedback dado de forma adequada, juntamente com as experiências de êxito que todo docente deve tentar propiciar aos alunos, adequando o nível de dificuldade e a especificidade das tarefas, tem relevância na formação de crença dos discentes.

Observa-se, como proposto pela TSC, que, na presente pesquisa, a experiência direta (a vivência), a experiência vicária (observar o sucesso ou fracasso do colega) e os aspectos fisiológicos e emocionais (a ansiedade percebida pelos alunos, em alguns momentos, é percebida como sinal de vulnerabilidade que os faz crer que não possuem capacidade para lidar com as tarefas propostas no domínio estudado) influenciaram a construção da autoeficácia desse grupo de alunos. Um quarto fator, também relevante, foi a questão da didática do professor (já comentada). É fundamental ressaltar, então, a importância do papel do professor para esses alunos.

Em relação aos alunos concluintes, verificou-se que os mesmos fatores se repetem como positivos, a saber: a didática utilizada pelo professor, a percepção da possibilidade de sucesso (experiência direta) e a observação de alunos que se saíram bem na disciplina (experiência vicária).

Em síntese, observou-se que alguns fatores surgiram como importantes de serem trabalhados pela equipe de pedagogos, psicólogos educacionais e professores da instituição para que os alunos obtenham maior sucesso no domínio estudado. Dentre esses fatores, destacam-se: a didática e as estratégias utilizadas pelos professores em sala de aula (que podem abarcar as questões das experiências direta e vicária de sucesso, bem como alguns fatores de persuasão verbal - o feedback do professor, por exemplo) e o fator emocional dos alunos diante da disciplina (ansiedade).

\section{CONSIDERAÇÕES FINAIS}

Os desafios e as descobertas que a pesquisa nos apresentou instigam-nos a apresentar as seguintes reflexões:

1 - Evidenciou-se a importância dos estudos sobre a autoeficácia para a formação dos novos docentes. A Teoria Social Cognitiva é uma teoria ainda pouco difundida no Brasil, mas já existem alguns estudos sobre a sua influência no desempenho escolar e na atuação do professor que muito pode contribuir para a práxis docente.

2 - Deparamo-nos nos resultados com expectativas de autoeficácia bastante robustas nos alunos iniciantes da disciplina e uma autoeficácia bastante cambiante mesmo no grupo de concluintes da disciplina. Pode-se analisar essa autoeficácia frágil em decorrência de fatores ambientais que os eles não controlam (exigência do professor, turma, possível ajuda que possa receber etc.).

3 - Observou-se que a maioria dos alunos se autorregula para realizar as tarefas da disciplina. Estudam alguns dias na semana, e não somente para fazer prova. Buscam ajuda na internet para estudar (videoaula) e não citam participar de monitorias.

4 - Foi notória, nos resultados, a importância do papel do professor na formação e na manutenção da 
autoeficácia dos alunos nas disciplinas de Cálculo, seja essa influência positiva ou negativa. Sua atuação tem relevância na construção da autoeficácia, tanto nos aspectos da persuasão verbal (através de sua forma de fornecer feedback sobre o desempenho dos alunos) quanto na utilização das estratégias e métodos didáticos na sua atuação na sala de aula.

5-A relevância dada pelos alunos à didática utilizada em classe pelo professor demonstra a necessidade da equipe pedagógica e dos professores buscarem novas metodologias de atuação na disciplina que deem suporte à construção da autoeficácia dos alunos. Nesse sentido, sugerimos a leitura dos trabalhos de Schunk $(1989,1991)$ e de Boruchovitch e Bzuneck, (2009), que sugerem que as atividades devem resguardar três características: devem ser próximas (podem ser cumpridas em um curto espaço de tempo); devem ser específicas (devem ser bem definidas, não podem ser genéricas, vagas) e, por fim, devem ser adequadas ao nível de dificuldade dos alunos (o que implica em trabalhar com diversas atividades).

6 - Outro ponto de destaque, em que cabe um trabaIho do Setor de Psicologia Educacional da instituição, é a influência dos fatores emocionais como dificultadores do sucesso dos alunos durante a disciplina. Esse fator surgiu em diversos pontos da pesquisa. Sabe-se, pela Teoria Social Cognitiva, que os fatores fisiológicos e emocionais são alguns dos que influenciam a formação da crença de autoeficácia.

Acreditamos que, pela importância do tema, ainda existam diversos aspectos da questão a serem pesquisados, e sugerimos novos estudos utilizando escalas específicas de medidas de autoeficácia e recursos estatísticos, que, pelo escopo da presente pesquisa, não foram utilizados. Colocamos também a não utilização desses como uma limitação de nosso estudo.

\section{REFERÊNCIAS}

Azzi, R. G. (2014). Introdução à Teoria Social Cognitiva. Série Teoria Social Cognitiva em Contexto Educativo (Vol. 1). São Paulo: Casa do Psicólogo.

Azzi, R. G.; Polydoro, S. A. J. (2006). Autoeficácia proposta por Albert Bandura: algumas discussões. In Azzi, R. G.; Polydoro, S. A. J. (Eds), Auto-eficácia em diferentes contextos (pp. 9-23). Campinas: Editora Alínea.

Bandura, A. (1986). Social foundations of thought and action: a social cognitive theory. Englewood Cliffs, NJ: Prentice-Hall.

Bandura, A. (1994). Self-efficacy. In Ramachaudran, V. S. (Ed.), Encyclopedia of human behavior (Vol. 4, pp. 71-81). New York: Academic Press.

Bandura, A. (1997). Self-efficacy: The exercise of control. New York: Freeman.

Barros, M.; Santos, A. C. B. (2010). Por dentro da auto-eficácia: um estudo sobre seus fundamentos teóricos, suas fontes e conceitos correlatos. Revista Espaço Acadêmico, (12), 1-9.
Boruchovitch, E.; Bzuneck, J. A. (Eds.). (2009). Motivação do aluno: contribuições da psicologia contemporânea (4a ed.). Petrópolis, RJ: Vozes.

Costa, A. E. B. (2008). Modelação. In Bandura, A.; Azzi, R.G.; Polydoro, S. (Eds.), Teoria social cognitiva: conceitos básicos (pp. 123-148). Porto Alegre: Artmed.

Garzela, F. A. C. (2013). A Disciplina de Cálculo I: Análise das Relações Entre as Práticas Pedagógicas do Professor e Seus Impactos nos Alunos. Tese de doutorado, Faculdade de Educação, Universidade Estadual de Campinas, Campinas, SP.

Pajares, F.; Olaz, F. (2008). Teoria social cognitiva e autoeficácia: Uma visão geral. In Bandura, A.; Azzi, R. G.; Polydoro, S. (Eds.), Teoria social cognitiva: conceitos básicos (pp. 97114). Porto Alegre: Artmed.

Pajares, F.; Schunck, D. H. (2004). Self-efficay in Education Revisited: Empirical and Applied Evidence. In McInerney, D. M.; Alexander, P.; van Etten, S. (Eds.), Big Theories Revisited (pp. 115-138). Charlotte, NC: IAP.

Pajares, F. (1996). Self-efficacy beliefs in academic settings. Review of Educational Research, 66(4), 543-578.

Pinto, E.; Carvalho, M. E.; Rabay, G. (2014). Gênero: um fator condicionante nas escolhas de cursos superiores. In Anais do $18^{\circ}$ REDOR (pp. 233-249). Pernambuco: Universidade Federal Rural de Pernambuco.

Pires, R. S. S. (2008). A motivação dos professores e alunos em ciências: um estudo sobre auto-eficácia no 3. ciclo e ensino secundário. Dissertação de Mestrado. Universidade de Lisboa - Faculdade de Ciências - Departamento de Educação. Lisboa: Portugal.

Poy, R.; Segarra, P.; Pastor, M. C.; Montañés, S.; Tormo, M. P.; Moltó, J. (2004). Emoción, autoeficácia y cognición. In Salanova, M.; Grau, R.; Martínez, I. M.; Cifre, E.; Llorens, S.; García-Renedo, M. (Eds.), Nuevos horizontes in la investigación sobre la autoeficácia (pp. 81-88). Castelló de la Plana: Publicacions de La Universitat Jaume I, D. L.

Rocha, V. C. (2011). Tempos de Superação para a Educação Paranaense? Uma leitura do discurso oficial a partir dos documentos orientadores das Semanas Pedagógicas. Dissertação de Mestrado em Educação, Universidade Estadual de Londrina, Paraná.

Schunk, D. H. (1991). Self-efficacy and academic motivation. Educational Psychologist, 26, 207-231.

Schunk, D. H. (1989). Self-efficacy and achievement behaviors. Educational Psychology Review, 1, 173-208.

Shih, S.; Alexander, J. M. (2000). Interacting effects of goal setting and self- or otherreferenced feedback on children's development of self-efficacy and cognitive skill within the Taiwanese classroom. Journal of Educational Psychology, 92, 536- 543.

Souza, L. F. N. I.; Brito, M. R. F. (2008). Crenças de auto-eficácia, autoconceito e desempenho em matemática. Estudos de Psicologia, 25 (2), 193-201.

Torisu, E. M. (2010). Crenças de auto-eficácia e Motivação 
para a Matemática: um estudo com alunos do Ensino Fundamental de uma escola pública de Ouro Branco/MG. Dissertação de mestrado, Universidade Federal de Ouro Preto, Ouro Preto, MG.
Torisu, E. M.; Ferreira, A. C. (2009). A teoria social cognitiva e o ensino-aprendizagem da matemática: considerações sobre as crenças de autoeficácia matemática. Ciências \& Cognição, Rio de Janeiro, v. 4, n. 3, p. 168-177.

Recebido: 05 de junho de 2018 Aprovado: 28 de novembro de 2019 